\title{
BrailleRing: The Shortest Long Braille-Display in the World - A Review of the State-of-the-Art and a New Approach
}

\author{
Wolfgang L. Zagler ${ }^{1,2(\bowtie)}\left(\mathbb{D}\right.$, Michael Treml², Dominik Busse ${ }^{2}$, \\ Mike Busboom ${ }^{2}$, and István Deák ${ }^{2}$ \\ 1 Vienna University of Technology (retired), Vienna, Austria \\ 2 Team TETRAGON, Vienna, Austria \\ office@tetragon.at
}

\begin{abstract}
After paying tribute to the ground-breaking invention of the tactile alphabet by Louis Braille, the paper describes the technological development of so-called refreshable Braille-Displays in significant steps from the late 1970s up till now. Despite quite many R\&D efforts over these 40 years, all BrailleDisplays presently available on the market in principle follow the same construction scheme as disclosed by Tetzlaff in 1981: Piezo-electric benders which move small pins up- and down [1]. In order to overcome several drawbacks of the classical solutions, we propose and investigate a radically new approach, where different combinations of rigid tactile points are placed on the surfaces of rotating cuboids which are arranged inside of a rotating cylinder. The lower half of the cylinder resembles the reading area for the finger, whereas a group of a few actuators by rotating said cuboids produces new text-content in the upper half. This can result not only in a complete new way of mobile and reasonably priced Braille reading equipment but also in a revival of Braille worldwide.
\end{abstract}

Keywords: Braille $\cdot$ Braille-Display $\cdot$ Braille reader

\section{Introduction}

When the French teacher, Louis Braille, developed a tactile system of dots to enable his blind students to read and write, he probably had little understanding of how his invention would positively impact literacy among blind people worldwide. With just six tactile dots, arranged in a $2 \times 3$ matrix, it became possible for blind people to gain literacy, do complicated math and read music notation, among many other things.

Today access to digitally provided text for blind and severely visually impaired people can be achieved in three ways: (i) Printing on thick paper to produce traditional hardcopy Braille, (ii) converting the text into synthetic speech (TTS, speech synthesizer) or (iii) using so called "refreshable Braille-Displays" from which the dot patterns of the Braille characters can be read with the fingertip. 


\section{Requirements}

It has to be mentioned that Braille is not a language but a font consisting of 63 different characters (for 6-dot Braille) or 255 characters (for 8-dot Braille) - not counting the "white space". For this reason Braille can be used for any language on earth as well as for Mathematics, Chemistry, Music and much more. Thus, the requirements for Braille in general and for Braille-Displays in particular have to fulfil the demands of a global market and a "one-size-fits-all" strategy will not necessarily be the best one. Nevertheless, a dot-to-dot spacing of about $2.5 \mathrm{~mm}$ and a minimum force of $200 \mathrm{mN}$ (for a single pin pressing against the skin of the fingertip) are readily agreed upon as quasistandards. What is even more important, above all other mechanical considerations, is the fact that the best and most precise tactile stimulation can only be achieved by sliding the finger across the Braille reading area. Raising and lowering pins beneath a static resting fingertip will not do satisfactorily [2].

\section{A Historic Review of Braille-Displays}

Despite all R\&D efforts of the past decades, up to now only two technologies for building refreshable Braille-Displays have found their way onto the market.

\subsection{Electromagnetic Actuators (Solenoids)}

Realistic electromagnetic Braille-Displays using solenoid plungers or electromagnetic flappers were first disclosed as early as 1973 e.g. by Lindenmüller and Schönherr [3], but there are still recent publications which try to come up with improvements $[4,5]$. Solenoids either need a lot of space and energy to produce sufficient forces or will, when miniaturized to fit beneath the footprint of a single Braille-dot, only provide low forces making latching mechanisms necessary (Fig. 1, left [3]).
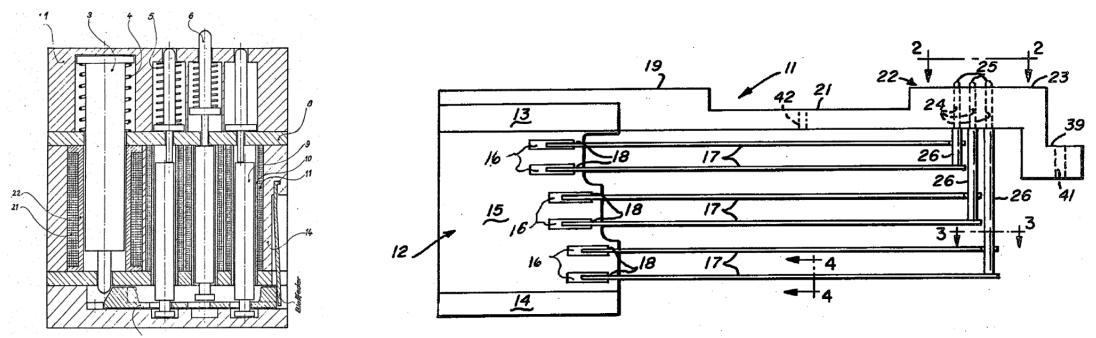

Fig. 1. Left: electromagnetic Braille-Display [3]; Right: piezo-electric benders [1]

\subsection{Piezo-Electric Actuators}

Piezo-electric actuators (bimorph benders) for Braille-Displays were introduced in 1979 by Tetzlaff [1] and still constitute the operating principle of all present commercially available Braille-Displays (Fig. 1, right). 


\section{The Search for Alternatives}

Presently used technologies have some significant drawbacks such as low forces, relatively big volumes, considerable sensitivity to dirt and moisture and especially high manufacturing and service costs. The search for better alternatives was immediately undertaken. A literature search in 2018 for improvements and alternative technologies revealed about 1,000 patents which match "Braille + Display" and also at least the same number of research papers. The main strands of R\&D deal with actuator technology, ways to reduce the number of actuators, or tactile stimulation methods which avoid actuators completely by direct stimulation of the fingertip's skin.

\subsection{Alternative Actuators for Forming Single Braille-Dots}

- Shape Memory Alloys (SMA) are materials which are able to "remember" their shape (length, bending) prior to a deformation and return to this shape after heating. Thus pairs of wires or coils of SMA can be used for moving a Braille-pin up and down. Material fatigue turned out to be the main problem [6].

- Thermal processes like in a steam engine e.g. by heating a small volume of paraffin and using the resulting expansion to drive a pin were proposed by [7]. Drawbacks are heat dissipation and low response times especially for the cooling phase.

- Electro Active Polymers (EAP) change their shape when exposed to an electric field. Promising research is under way [8] but without significant breakthroughs.

- Optical/chemical processes like the expansion of liquid crystal carbon nanotube (LC-CNT) when exposed to light stemming from single LEDs or from an entire display surface (tablet-PCs) are proposed by [9].

- Micromachines (MEMS) which can be mass-produced by stereo-lithography are a promising approach to build thermal or ultrasound motors [10] able to move Braille-pins even to different heights, but not yet ready for commercialization.

- Pneumatic or hydraulic drives: Here holes or other cavities are sealed with an elastic film. Raising the pressure in the cavity (by air- or fluid-pressure) will cause the film to form a bubble (blister) which will resemble a single Braille-dot [11]. Often so called Electro-Rheological Fluids (ERF) are used which change from low to high viscosity when an electric field is applied. Thus flow and pressure for forming the "bubbles" can be controlled just by electric fields instead of expensive and complicated mechanical valves [12].

\subsection{Direct Skin Stimulation - No Moving Parts}

To avoid the necessity for any moving parts (pins, actuators) several researchers experimented with direct stimulation of the neural tissue of the fingertip.

- Electrocutaneous stimulation: The Braille-Display consists of a flat surface with an electrode (monopolar or better bipolar) for every Braille-dot. When the fingertip moves across this surface, active dots (electrodes) will send a well-defined electric current into the user's skin, causing a feeling comparable to a mechanical stimulus. 
Unfortunately, many parameters (impedance, conductance and local sensitivity) are subject to temporal and spatial changes and reliable and comfortable stimulation could not easily be achieved [13].

- Electromagnetic radiation by focusing infrared laser light to stimulate deeper skin areas is proposed in [14].

- Electrostatic forces: Locally changing the adhesive shear-forces exerted on the sliding fingertip by applying (well isolated) dot-shaped electrostatic charges [15].

\subsection{Reducing the Number of Actuators by Using Moving Elements}

A major drawback of mechanical solutions is the number of delicate components needed. In piezo-electric Braille-Displays, each pin has its own actuator, adding up to a whopping 320 actuators in a standard 8-dot display with 40 characters. Newer approaches try to solve this issue by moving other parts of the device additionally or instead of the pins.

- Pins on a disk or drum: Braille characters are displayed on a rotating disk or drum. The pins are set and reset when passing by a group of (a few) actuators (Fig. 2, left and center $[16,17])$.

- Dots on polygon surfaces: Instead of pins shifting up and down in a hole, these inventions place rigid Braille-dot patterns on the 3 or 8 lateral surfaces of three- or eight-sided prisms. Using eight-sided prisms turned out to be space consuming and unsuitable for 8-dot Braille (Fig. 2, right [18]). The use of three-sided prisms would allow for displaying dots with two different haptic characteristics - however, the problem of actuating every single dot cannot be avoided this way [19].
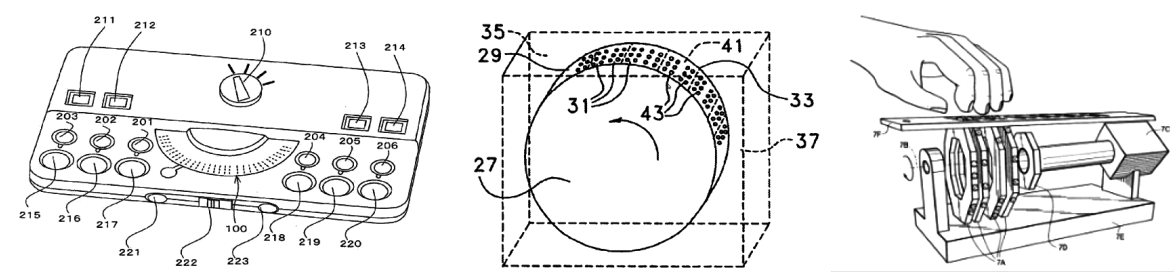

Fig. 2. Braille on a disk [16], on a drum [17] or on the sides of a polygon [18]

\section{State-of-the-Art Display Configurations}

\subsection{Lines Ranging from 10 to 80 Characters - 6 and 8 Dot Braille}

The most common configuration for today's Braille-Displays are single lines with 10 to 80 characters. According to a study by Ramstein [20], lines with 40 Braille-cells allow for the most fluent reading. Shorter lines certainly are less expensive and can be used in mobile settings, however, the reader is forced to frequent backward movements which are time consuming and inconvenient (Fig. 3, left). Very long lines ask for extensive arm movements and thus cause unwanted fatigue (Fig. 3, center). 


\subsection{Multiline and Graphic (Matrix) Displays}

Efforts to ease reading by displaying multiple lines or even an entire page of Braille reach back until 1981 with the invention of the "Rose Reader" [21]. Commercialization, however, failed due to enormous complexity and costs. Even more recent developments like the "Hyperbraille" with a $120 \times 60$ pin matrix (Fig. 3, right) suffer from a price tag between EUR 45,000 and EUR 50,000 [22].
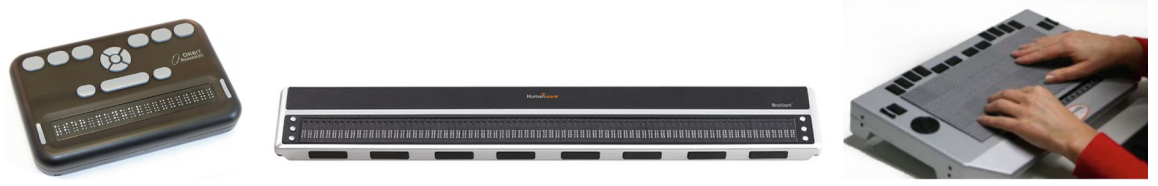

Fig. 3. Typical Braille-Display configurations: left: Orbit 20 (www.aph.org/orbit-reader-20); centre: Brailliant 80 (www.humanware.com/brailliant); right: Hyperbraille [21]

\subsection{Static Single-Cell and Virtual Braille-Displays}

To make Braille-Displays more affordable especially for developing countries, several researchers tried to reduce Braille-lines to just one single cell [4]. As pins are raised and lowered below a static resting finger, the missing lateral movements lead to very low reading rates and complete loss of spatial orientation along the line of text.

To overcome the page or line orientation problem, virtual Braille-Displays have been designed, where one [20] or few [23] Braille-cells can be moved along a virtual line or across a virtual page showing the contents of the location thus addressed.

To simulate lateral skin stimulation Fricke [2] proposed "peristaltic" movements of densely spaced pins and Lévesque [24] laterally moving actuators (Fig. 4, right).
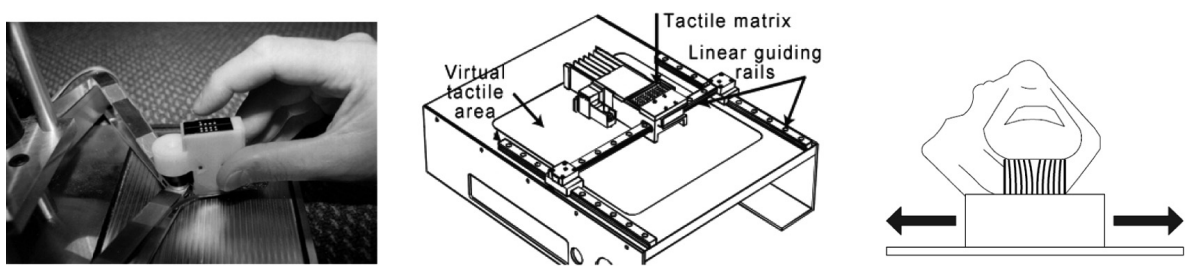

Fig. 4. Left: Pantobraille [20]; centre: Braille on a carriage [23]; Right: lateral stimulation [24]

\section{Striving for a New Approach - The "BrailleRing"}

\subsection{The Concept}

Starting in 2014 with a basic idea for a robust, pocket-sized and reasonably priced Braille-Display, two students from the TU Wien were successful in proving the concept in their theses $[25,26]$ and in building an enlarged (2.5:1) prototype. Since then, the concept has been refined and pre-tested by blind users with simple mock-ups. A national patent [27] was granted, international applications are pending. 
The BrailleRing strives not to replace existing Braille-lines, just as a "Kindle" cannot replace a PC. Moreover, it should become an alternative for those applications where existing technology is too bulky, too heavy, too delicate or too expensive.

The BrailleRing will be small and, nevertheless, capable of showing long lines of text. This is achieved by displaying the Braille-characters on the inside of a rotating ring. While the reading finger rests at the bottom of the device, the user will slide the entire device like a computer mouse across a table surface. By friction the ring will rotate proportional to the speed and direction of the hand movement, letting the Braillecharacters glide beneath the reading finger (Fig. 5, left).
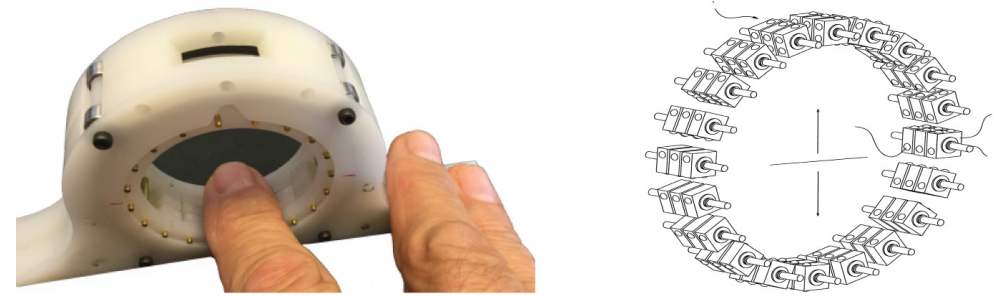

Fig. 5. Left: Reading with the BrailleRing; Right: Braille-cuboids in a ring-shaped assembly

\subsection{Realization}

Instead of single moving pins, the BrailleRing forms the dot-combinations of Braille by turning small cuboids with rigid Braille-dots on their lateral surfaces. Figure 6 (left) shows the transition from " $\mathrm{R}$ " to " $\mathrm{H}$ " for the conventional approach by lowering pin 3 (bottom-left corner). In the BrailleRing the transition is accomplished by a $90^{\circ}$ clockwise turn of cuboid 3 (Fig. 6, right). The 64 combinations of Braille-dots are produced by turning one or more cuboids to the desired position (for 8-dot Braille a fourth cuboid will be added). The turning of the cuboids is achieved in the upper half of the rotating ring when the elements pass by an array of actuators [27].

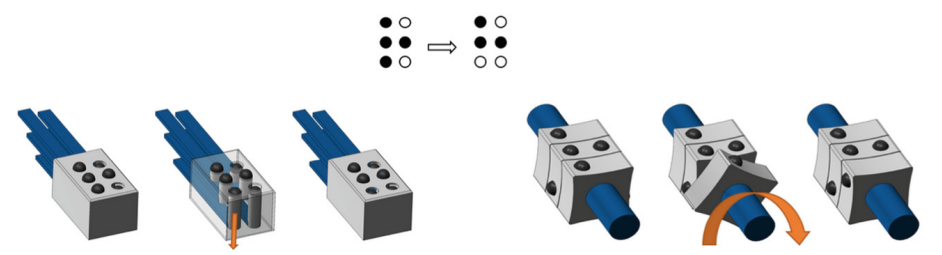

Fig. 6. Transition from "R" to "H": left: conventional display; right: BrailleRing method

\subsection{Features and Benefits}

The BrailleRing has a huge potential to significantly increase the mobility of BrailleDisplays. The design allows building very compact devices where the line length is completely defined by the user. A later envisaged motor drive could provide even endless lines. The concept will also increase robustness, making the display more suitable for outdoor activities where humidity, sand and dust could be an issue. If built 
in such a way that the rotating ring can be changed easily, the user would be able to clean the device on his or her own. Different types of rings can be provided according to specific user preferences (e.g. different shaped or sized dots). It should be possible to build a device with much lower production and service costs than conventional piezoelectric Braille-Displays. Therefore, the BrailleRing should also be ideally suited for a market in developing countries.

\section{Discussion}

\subsection{Present State of the Development}

Presently (March 2018), several mock-ups and simulation devices in real size exist or are under development. These aim to understand the reading experience inside a ring and demonstrate the final size of the device (mobile). As the Braille-dots are not formed by moving pins, the BrailleRing will offer much more degrees of freedom in haptic Braille representation. We intend to invest significant efforts to optimize the tactile user experience before the final design.

Another development goal for the second quarter of 2018 will be the search for optimized actuators that are able to turn the cuboids reliably independent of reading speed and direction while at the same time, minimizing the power consumption, which is crucial for a mobile device.

\subsection{User Involvement and Trials}

While the discovery of the mechanism with disruptive potential was serendipitous, a user-centric approach is what steers further development. Before IP protection, user involvement was on a nondisclosure basis, so only one single (blind) Braille expert was included from the outset. This was changed after the patent was granted and user studies started immediately. They can be described in two major phases:

First, through local news reports about the invention, a call for user-participation triggered 25 curious responses by blind people. Around half of them were invited to semi-structured interviews conducted in-person. Simple mockups were used to explore the new way of reading and the concept of a truly mobile Braille-Display.

In the second phase, the list of candidates for user studies grew to 50 by word-ofmouth. Here the user trials will focus on usability, ergonomics and especially on tests with different Braille pattern sizes and dimensions. This is crucial, as some first trialusers mentioned that the felt character to character distance is smaller when read from a concave surface. Afterwards, user studies with an adapted mockup will follow where reading speed and error rate compared to conventional flat Braille-Displays will be measured quantitatively.

\section{References}

1. Tetzlaff, J.F.: Patent US 4283178 A (1981) 
2. Fricke, J., Baehring, H.: Displaying laterally moving tactile information. In: Zagler, W.L., Busby, G., Wagner, R.R. (eds.) ICCHP 1994. LNCS, vol. 860, pp. 461-468. Springer, Heidelberg (1994). https://doi.org/10.1007/3-540-58476-5_169

3. Lindenmüller, H.P., Schönherr, K.P.: Patent US 3987438 (1975)

4. Anu, U.S., Thomas, A.M., Krishna, C.R., Akhil, A.N.S.K., Potti, S.S.: A low cost refreshable Braille display; a novel approach for the primary education of blind in India. Int. J. Adv. Technol. Eng. Sci. 5(4), 286-292 (2017)

5. Shah, S.: Patent WO 2017203536 A1 (2017)

6. Chen, X.: Patent WO 2016197928 A1 (2016)

7. Green, S.R., Gregory, B.J., Gupta, N.K.: Dynamic Braille display utilizing phase-change microactuators. In: Proceedings of IEEE Sensors, pp. 307-310 (2006)

8. Bar-Cohen, Y.: Refreshable Braille displays using EAP actuators. In: SPIE Smart Structures and Materials+Nondestructive Evaluation and Health Monitoring, vol. 7642, pp. 764206764206-5 (2010)

9. Camargo, C.J., et al.: Batch fabrication of optical actuators using nanotube-elastomer composites. J. Micromech. Microeng. 22(7), 75009 (2012)

10. Velázquez, R., Hernández, H., Preza, E.: A portable piezoelectric tactile terminal for Braille readers. Appl. Bionics Biomech. 9(1), 45-60 (2012)

11. Wilhelm, E., Schwarz, T., Jaworek, G., Voigt, A., Rapp, B.E.: Towards displaying graphics on a cheap, large-scale Braille display. In: Miesenberger, K., Fels, D., Archambault, D., Peňáz, P., Zagler, W. (eds.) ICCHP 2014. LNCS, vol. 8547, pp. 662-669. Springer, Cham (2014). https://doi.org/10.1007/978-3-319-08596-8_102

12. Luning, X., Han, L., Yufei, L., Shen, R., Kunquan, L.: Operational durability of a giant ER valve for Braille display. Smart Mater. Struct. 26(5), 54003 (2017)

13. Liu, Z., Luo, Y., Cordero, J., Zhao, N., Shen, Y.: Finger-eye: a wearable text reading assistive system for the blind and visually impaired. In: 2016 IEEE International Conference on Real-Time Computing and Robotics, RCAR 2016, pp. 123-128 (2016)

14. Yu, W.J., Brownell, A.A.: Patent US 20140022162 Al (2014)

15. Bateman, A., et al.: A user-centered design and analysis of an electrostatic haptic touchscreen system for students with visual impairments. Int. J. Hum. Comput. Stud. 109 (May 2016), 102-111 (2018)

16. Shimamura, Y.: Patent EP 15222983 A1 (2004)

17. Roberts, J.W.: Patent US 20020045151 A1 (2002)

18. Al-Qudsi, M.: Patent US 20130203022 A1 (2013)

19. Campos de Leon, G.M.: Patent US 9524655 B1 (2016)

20. Ramstein, C.: Combining haptic and braille technologies: design issues and pilot study. In: Annual ACM Conference on Assistive technologies, pp. 37-44 (1996)

21. Rose, L., Rose, S.E.: Patent US 4226936 (1981)

22. Esteve, J.: Towards smart tactile tablets for the visually impaired persons. In: EPoSS Annual Forum (2011)

23. Chan, J.S., Maucher, T., Schemmel, J., Kilroy, D., Newell, F.N., Meier, K.: The virtual haptic display: a device for exploring 2-D virtual shapes in the tactile modality. Behav. Res. Methods 39(4), 802-810 (2007)

24. Lévesque, V., Pasquero, J., Hayward, V., Legault, M.: Display of virtual braille dots by lateral skin deformation: feasibility study. ACM Trans. Appl. Percept. 2(2), 132-149 (2005)

25. Treml, M.: Grobkonzeption und Steuerung eines Brailledisplays mit gruppierten Punkten. Diplomarbeit TU Wien (2016)

26. Busse, D.: Konstruktion eines Braille-Displays. Diplomarbeit TU Wien (2016)

27. Treml, M., Zagler, W., Busse, D.: Vorrichtung zur Darstellung von tastbaren Zeichen. Patent AT 518530 A4 (2016) 
Open Access This chapter is licensed under the terms of the Creative Commons Attribution 4.0 International License (http://creativecommons.org/licenses/by/4.0/), which permits use, sharing, adaptation, distribution and reproduction in any medium or format, as long as you give appropriate credit to the original author(s) and the source, provide a link to the Creative Commons license and indicate if changes were made.

The images or other third party material in this chapter are included in the chapter's Creative Commons license, unless indicated otherwise in a credit line to the material. If material is not included in the chapter's Creative Commons license and your intended use is not permitted by statutory regulation or exceeds the permitted use, you will need to obtain permission directly from the copyright holder. 